\title{
Um caso típico de Síndrome de Sweet
}

Maria Lúcia Ramos, ${ }^{*}$ Luiz Miguel Santiago, ${ }^{* *}$ Teresa Tomé***

\section{RESUMO}

A Síndrome de Sweet é uma dermatose neutrofílica. Associa-se, em 50\% dos casos, a outras patologias como doenças infecciosas, inflamatórias, auto-imunes e, sobretudo, neoplásicas (20 a 25\%).

O objectivo deste trabalho é alertar o médico de família (MF) para esta patologia, enumerar os critérios necessários ao seu diagnóstico e aumentar o índice de suspeição.

Relata-se o caso de uma mulher que apresenta um síndrome gripal com cinco dias de evolução. Dois dias após início deste quadro referiu aparecimento súbito de lesões cutâneas circulares em pápula eritematosa e com descoloração central. Negou prurido, mas com dor ao toque. Foi-lhe diagnosticada Síndrome de Sweet e iniciou tratamento com corticoterapia oral, com resolução clínica completa em apenas alguns dias.

O estudo para exclusão de patologia neoplásica associada foi negativo. Tem indicação para realizar hemograma semestral e os rastreios oncológicos de acordo com a idade e sexo.

Palavras-chave: Síndrome de Sweet; Dermatose; Febre.

\section{INTRODUÇÃO}

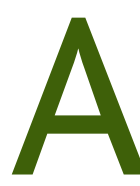

Síndrome de Sweet é uma dermatose neutro-

fílica caracterizada por início súbito de febre, leucocitose e lesões cutâneas eritemato-violáceas, com infiltrado dérmico por neutrófilos. Há uma predominância desta patologia no sexo feminino. ${ }^{1} \mathrm{~A}$ sua patogénese permanece desconhecida mas pensa-se que resulta de uma reacção de hipersensibilidade a um antigénio de origem tumoral, bacteriano ou viral. ${ }^{2}$

Associa-se, em $50 \%$ dos casos, a outras patologias como doenças infecciosas, inflamatórias, auto-imunes e, sobretudo, neoplásicas, podendo estar também associada a gravidez e a fármacos. ${ }^{3,4}$ Aproximadamente 20-25\% dos doentes com esta patologia têm uma neoplasia associada (na maioria dos casos hematológica, mas também pode acompanhar o cancro da mama, gastrointestinal e genito-urinário). ${ }^{5,6}$

Esta síndrome pode manifestar-se em simultâneo com a neoplasia ${ }^{7}$, antecedê-la em até 11 anos $^{2}$ ou sina-

* Interna do internato de Medicina Geral e Familiar da USF CelaSaúde,

**Professor Doutor em medicina pela Universidade de Coimbra, Professor associado convidado na Universidade da Beira Interior, Assistente Graduado Sénior na UCSP de Eiras;

***Assistente Graduada Sénior e Coordenadora da USF CelaSaúde, Mestre em Saúde Pública e Coordenadora do Centro de Apoio ao Jovem. lizar uma recorrência de uma doença em remissão. ${ }^{7}$

O objectivo desta apresentação é alertar o médico de família (MF) para esta patologia, enumerando os critérios necessários ao seu diagnóstico, facilitando a sua suspeição e encaminhando atempada e adequadamente o doente para confirmação diagnóstica.

\section{DESCRIÇÃO DO CASO}

P.P., sexo feminino, 47 anos, raça caucasiana, casada mas em processo de divórcio, com o $9^{\circ}$ ano de escolaridade, desempregada há 2 anos.

Quanto a antecedentes pessoais fisiológicos, tem uma alimentação variada, nega hábitos etílicos e tabágicos, faz caminhadas regulares, é normoponderal (IMC $22,5 \mathrm{~kg} / \mathrm{m}^{2}$ ), teve a menarca aos 12 anos, IV Gesta II Para (interrupção voluntária da gravidez aos 18 anos, feto morto aos 23, nasceu a primeira filha aos 26 anos e a segunda aos 40 anos). Nega antecedentes pessoais patológicos relevantes, incluindo medicação crónica, alergias alimentares ou medicamentosas. Pertence a uma família alargada, altamente funcional de acordo com o Apgar familiar de Smilkstein, da classe média baixa de Graffar e sem critérios de risco familiar pelas escalas de Imperatori e Segovia-Dreyer. ${ }^{8}$

Recorre à consulta com febre (temperatura axilar: 


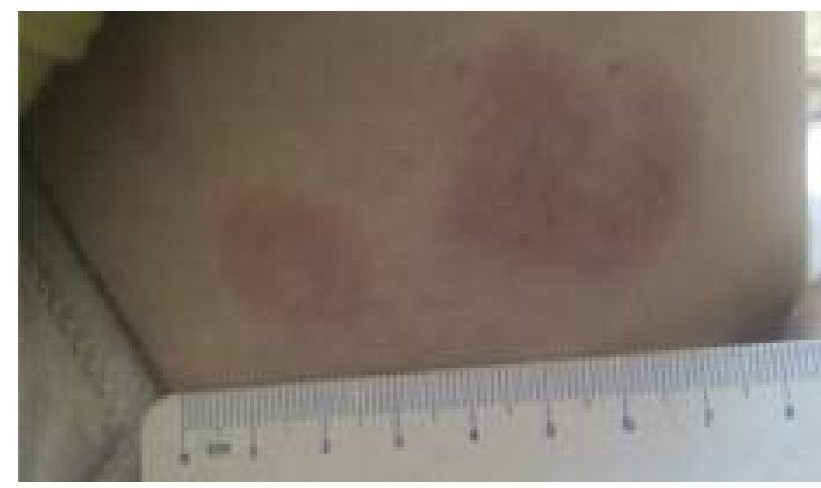

Figura 1. Duas pápulas eritematosas, circulares, na face interna do braço direito. Uma lesão tem cerca de $1,5 \mathrm{~cm}$ e a outra aproximadamente $3 \mathrm{~cm}$, tendo cada uma delas uma descoloração amarelada central.

$38-39^{\circ} \mathrm{C}$ ), tosse seca e mialgias generalizadas com 5 dias de evolução. Dois dias após início do quadro febril surge subitamente rash cutâneo na face interna do braço direito (figura 1). Nega prurido e refere que a lesão cutânea é dolorosa ao toque digital e até com a própria roupa. Recorreu por iniciativa própria à farmácia e tem aplicado nos últimos três dias um corticóide tópico $(0.1 \%$ valerato de dexametasona creme) que não surtiu efeito e foi descontinuado antes da primeira consulta.

Ao exame físico, não apresenta alterações na inspecção da cavidade oral, nem na auscultação cardiopulmonar. Observam-se duas erupções cutâneas em pápulas eritematosas, circulares, com uma descoloração amarelada central na face interna do braço direito. Uma lesão tem cerca de $1,5 \mathrm{~cm}$ e a outra aproximadamente $3 \mathrm{~cm}$. A restante pele apresen- ta-se íntegra.

Foram colocadas as hipóteses diagnósticas do Quadro I, pediram-se análises laboratoriais (hemograma com leucograma, velocidade de sedimentação, proteína C reactiva, ANCA - Anticorpo anti-citoplasma do neutrófilo), referenciou-se a utente para a consulta de Dermatologia e deu-se indicação para fazer antipirético caso necessitasse.

Na consulta de seguimento, cerca de um mês e meio depois, já não apresenta síndrome gripal.

Na consulta de Dermatologia foi efectuada biópsia da lesão cujo resultado histopatológico foi compatível com infiltração neutrofílica na derme, sem atingimento vascular. Ao exame objectivo, as lesões cutâneas praticamente desapareceram.

A utente trouxe o resultado da avaliação laboratorial requerida na primeira consulta e que foi colhida alguns dias após o inicio dos sintomas [(hemoglobina 11,5 $\mathrm{mmol} / \mathrm{L}$; leucócitos $16,6 \mathrm{G} / \mathrm{L}$ com $96 \%$ de polimorfonucleares; velocidade de sedimentação $20 \mathrm{~mm} / \mathrm{h}$; anticorpo anti-citoplasma do neutrófilo (ANCA) negativo; proteína C reactiva $3,42 \mathrm{mg} / \mathrm{dl}]$.

\begin{tabular}{|l|l|l|l|}
\hline \multicolumn{2}{|l|}{ QUADRO I. Diagnósticos diferenciais. } \\
Vasculites & \multicolumn{1}{|c|}{ Infecções } & Carcinomas malignos & \multicolumn{1}{|c|}{$\begin{array}{l}\text { Outros distúrbios } \\
\text { inflamatórios }\end{array}$} \\
\hline Urticária & $\begin{array}{l}\text { Pioderma (foliculite, } \\
\text { furúnculos, celulite) }\end{array}$ & $\begin{array}{l}\text { Linfoma cutâneo } \\
\text { (micose fungóide, } \\
\text { linfoma de células T) }\end{array}$ & $\begin{array}{l}\text { Paniculite (incluindo } \\
\text { eritema nodoso) }\end{array}$ \\
\hline $\begin{array}{l}\text { Vasculite cutânea } \\
\text { de pequenos vasos }\end{array}$ & Vasculite séptica & Metástases & $\begin{array}{l}\text { Reacção severa à } \\
\text { mordida de um } \\
\text { artrópode }\end{array}$ \\
\hline $\begin{array}{l}\text { Granulomatose com } \\
\text { poliangite (Wegener) }\end{array}$ & $\begin{array}{l}\text { Infecção fúngica } \\
\text { superficial } \\
\text { Infecção fúngica } \\
\text { profunda: } \\
\text { criptococose } \\
\text { Blastomicose } \\
\text { Tuberculose } \\
\text { Leishmaniose } \\
\text { cutânea }\end{array}$ & $\begin{array}{l}\text { Lupus Eritematoso } \\
\text { Doenças Granulomatosas } \\
\text { (sarcoidose, dermatite } \\
\text { granulomatosa intersticial, } \\
\text { granuloma actínico...) }\end{array}$ \\
lododerma \\
Bromoderma
\end{tabular}


Fez-se o diagnóstico definitivo de Síndrome de Sweet e foi prescrita metilprednisolona $40 \mathrm{mg} /$ dia (toma única) na primeira semana, $30 \mathrm{mg}$ na segunda semana, 20 $\mathrm{mg}$ na terceira semana e $10 \mathrm{mg}$ nas duas semanas seguintes às 8 horas.

\section{COMENTÁRIO}

O MF, sendo muitas vezes o primeiro contacto dos utentes com sistema de saúde, tem o papel de abordar inicialmente várias patologias. Daí a importância de conhecer as manifestações clínicas cardinais desta síndrome e que são: erupção cutânea, infiltrado neutrofílico dérmico sem atingimento vascular (verificado na biópsia); febre (40-80\% dos doentes) e neutrofilia periférica. ${ }^{3,9}$

As lesões cutâneas são normalmente evocadoras da doença e consistem em pápulas ou placas eritematosas de coloração vermelho ou violeta com uma superfície irregular pseudovesicular e uma descoloração central, amarelada. As placas podem causar dor e/ou sensação de queimadura, mas não são pruriginosas. São mais frequentemente encontradas na face, pescoço e extremidades superiores, especialmente no dorso das mãos. Cerca de 3 a $30 \%$ dos pacientes apresentam lesão na cavidade oral, podendo apresentar-se como pústula e evoluir para úlcera mais tarde. Podem ser lesões múltiplas, generalizadas em qualquer parte do corpo, podendo também haver uma só lesão localizada. Nas

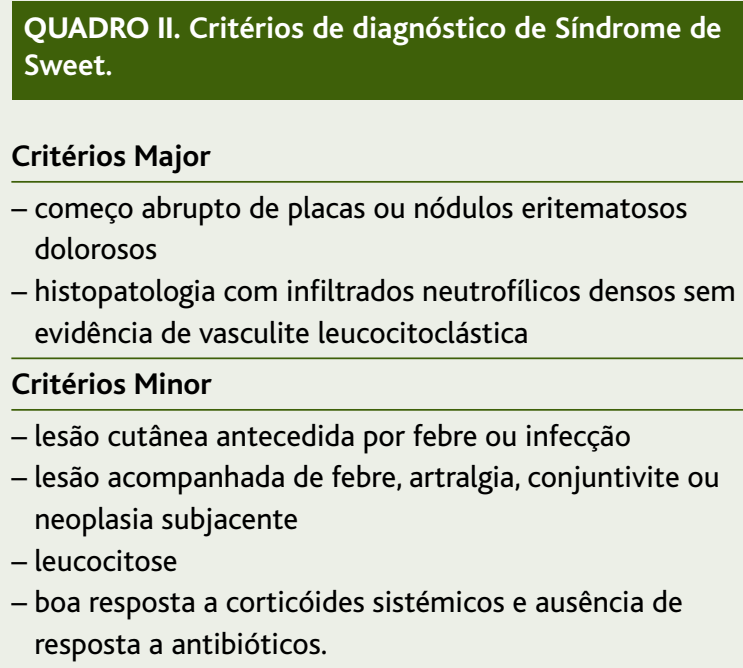

extremidades inferiores, as lesões são frequentemente confundidas com eritema nodoso, particularmente em doentes com a variante subcutânea rara de Síndrome de Sweet..$^{10-12}$

Para além das características acima referidas, podem ocorrer: insuficiência renal aguda, osteomielite estéril, alveolite neutrofílica, patologia ocular (conjuntivite, episclerite e iridoclerite). Cerca de um terço dos doentes refere artralgia, mialgia e artite (poliarticular, assimétrica, inflamatória, não erosiva e de actividade paralela ao curso da doença). Todas estas manifestações respondem a corticoterapia sistémica. ${ }^{3,10,13,14}$

As alterações laboratoriais são inespecíficas, incluindo uma elevação da velocidade de sedimentação e da proteína C-reativa, neutrofilia periférica, diminuição ligeira da hemoglobina, elevações ligeiras da fosfatase alcalina sérica, da aspartato aminotransferase e da gama-glutamil transferase. Têm sido descritos auto-anticorpos contra citoplasma dos neutrófilos (ANCA) num padrão perinuclear, com padrão de fluorescência fraco e difuso. ${ }^{15}$

Para o diagnóstico de Síndrome de Sweet são necessários dois critérios major e dois minor (ver quadro II). ${ }^{16}$

Caracteristicamente, à histopatologia são visíveis infiltrados nodulares neutrofílicos perivasculares, com cariorréxis neutrofílica. Embora não exista vasculite primária, os vasos sanguíneos podem ser secundariamente envolvidos na resposta imunológica, um achado infrequente. ${ }^{11,17-19}$

A Síndrome de Sweet faz diagnóstico diferencial com diversas lesões cutâneas (ver quadro I) e pode estar associada a qualquer uma das patologias acima citadas.

A associação desta síndrome a neoplasia ocorre em 20-25\% dos casos, ${ }^{7}$ podendo as manifestações cutâneas ocorrer em simultâneo com a neoplasia, ${ }^{7}$ antecedê-la em até 11 anos $^{2}$ ou sinalizar uma recorrência de uma doença em remissão. ${ }^{7}$

Não existem no momento atual normas de orientação clínica ou documentos de consenso de sociedades científicas relativamente a doentes com primeira manifestação de Síndrome de Sweet, sem aparente patologia associada. A utente foi submetida a avaliação para exclusão de patologia neoplásica à luz das recomendações de Charles e Cohen, ${ }^{2}$ com resultados negativos. Segundo os autores, em pessoas assintomáticas sem antecedentes neplásicos conhecidos e com uma pri- 
meira manifestação de Síndrome de Sweet, recomenda-se um rastreio de doença neoplásica adequado à idade (os autores sugerem um rastreio guiado pelas recomendações da American Cancer Society, sendo que adaptámos as recomendações à nossa realidade e aplicámos as normas da Direção Geral de Saúde para esse efeito). ${ }^{2}$ Tendo em conta que $85 \%$ dos cancros associados a esta síndrome são hematológicos ${ }^{7}$, podendo suceder esta doença em muitos anos, a doente tem indicação para realização de hemograma com leucograma a cada 6-12 meses, ${ }^{2}$ encontrando-se programado esse exame.

\section{REFERÊNCIAS BIBLIOGRÁFICAS}

1. Sweet RD.An acute febrile neutrophilic dermatosis. Br J Dermatol 1964 Aug-Sep; 76: 349-56.

2. Anzalone $\mathrm{CL}$, Cohen PR. Acute febrile neutrophilic dermatosis (Sweet's syndrome). Curr Opin Hematol 2013 Jan; 20 (1): 26-35.

3. Kemmett $D$, Hunter JA. Sweet's syndrome: a clinicopathologic review of twenty-nine cases. J Am Acad Dermatol 1990 Sep; 23 (3 Pt 1): 503-7.

4. Reuss-Borst MA, Pawelec G, Saal JG, Horny HP, Müller CA, Waller HD. Sweet's syndrome associated with myelodysplasia: possible role of cytokines in the pathogenesis of the disease. Br J Haematol 1993 Jun; 84 (2): 356-8.

5. Cohen PR, Talpaz M, Kurzrock R. Malignancy-associated Sweet's syndrome: review of the world literature. J Clin Oncol 1988 Dec; 6 (12): 1887-97.

6. Cohen PR, Holder WR, Tucker SB, Kono S, Kurzrock R. Sweet syndrome in patients with solid tumors. Cancer 1993 Nov; 72 (9): 2723-31.

7. Paydas S. Sweet's syndrome: a revisit for hematologists and oncologists. Crit Rev Oncol Hematol 2013 Apr; 86 (1): 85-95.

8. Rebelo L, editor. A família em Medicina Geral e Familiar: conceitos e práticas. Lisboa: Verlag Dashofer; 2011. p. 115.

9. Von den Driesch P. Sweet's syndrome (acute febrile neutrophilic dermatosis). J Am Acad Dermatol 1994 Oct; 31 (4): 535-56.

10. Guhl G, García-Díez A. Subcutaneous sweet syndrome. Dermatol Clin 2008 Oct; 26 (4): 541-51.

11. Cohen PR, HolderWR, Rapini RP. Concurrent Sweet's syndrome and ery- thema nodosum: a report, world literature review and mechanism of pathogenesis. J Rheumatol 1992 May; 19 (5): 814-20.

12. Waltz KM, Long D, Marks JG Jr, Billingsley EM. Sweet's syndrome and erythema nodosum: the simultaneous occurrence of 2 reactive dermatoses. Arch Dermatol 1999 Jan; 135 (1): 62-6.

13. Moreland LW, Brick JE, Kovach RE, DiBartolomeo AG, Mullins MC. Acute febrile neutrophilic dermatosis (Sweet syndrome): a review of the literature with emphasis on musculoskeletal manifestations. Semin Arthritis Rheum 1988 Feb; 17 (3): 143-53.

14. Hisanaga K, Iwasaki Y, Itoyama Y, Neuro-Sweet Disease Study Group. Neuro-Sweet disease: clinical manifestations and criteria for diagnosis. Neurology 2005 May 24; 64 (10): 1756-61.

15. Kemmett D, Harrison DJ, Hunter JA. Antibodies to neutrophil cytoplasmic antigens: serologic marker for Sweet's syndrome. J Am Acad Dermatol 1991 Jun; 24 (6 Pt 1): 967-9.

16. Su WP, Liu HN. Diagnostic criteria for Sweet s Syndrome. Cutis 1986 Mar; 37 (3): 167-74.

17. Requena L, Kutzner H, Palmedo G, Pascual M, Fernández-Herrera J, Fraga J, et al. Histiocytoid Sweet syndrome: a dermal infiltration of immature neutrophilic granulocytes. Arch Dermatol 2005 Jul; 141 (7): 83442.

18. Camarillo D, McCalmont TH, Frieden IJ, Gilliam AE. Two pediatric cases of nonbullous histiocytoid neutrophilic dermatitis presenting as a cutaneous manifestation of lupus erythematosus. Arch Dermatol 2008 Nov; 144 (11): 1495-8.

19. Wu AJ, Rodgers T, Fullen DR. Drug-associated histiocytoid Sweet's syndrome: a true neutrophilic maturation arrest variant. J Cutan Pathol 2008 Feb; 35 (2): 220-4.

\section{CONFLITOS DE INTERESSE}

Nada a declarar.

\section{ENDEREÇO PARA CORRESPONDÊNCIA}

Maria Lúcia Fialho Machado da Silva Ramos Unidade de Saúde Familiar CelaSaúde

Rua Augusto Rocha, 6 - 8; 3030-063 Coimbra

marialuciafialho@gmail.com

Recebido em 03/08/2012

Aceite para publicação em 14/03/2013 
ABSTRACT

\section{A TYPICAL CASE OF SWEET'S SYNDROME}

Sweet's Syndrome is a neutrophilic dermatosis. It is associated in $50 \%$ of cases with infectious, inflammatory, autoimmune, and neoplastic diseases (in $20-25 \%$ of cases). The aim of this presentation is to alert the family physician to this condition and to describe the findings necessary for the diagnosis. We report the case of a woman with flu-like symptoms of five days' duration. Two days after the beginning of these complaints, she reported the sudden onset of circular skin lesions in the form of erythematous papules with central discoloration. She denied pruritus, but complained of tenderness of the lesions. After an initial evaluation, the patient was referred to a dermatologist, who performed a skin biopsy. The histopathological examination revealed a neutrophilic infiltration of the dermis, sparing vascular structures. The diagnosis of Sweet's Syndrome was made and corticosteroid therapy was started, with complete resolution of the lesions in a few days. Initial testing for exclusion of an associated neoplasm was negative. The patient should perform a complete blood count every six months and cancer screening tests appropriate for her age and gender.

Keywords: Sweet's Syndrome; Dermatosis; Fever. 